\title{
Association of COVID-19 distribution with air quality, sociodemographic factors, and comorbidities: an ecological study of US states
}

\author{
Mohammad Sarmadi $^{1,2}$ D Vahid Kazemi Moghanddam ${ }^{3} \cdot$ Aisha S. Dickerson $^{4} \cdot$ Luigi Martelletti $^{5}$
}

Received: 9 July 2020 / Accepted: 29 September 2020 / Published online: 14 October 2020

(C) Springer Nature B.V. 2020

\begin{abstract}
This ecological study investigated the association between COVID-19 distribution and air quality index (AQI), comorbidities and sociodemographic factors in the USA. The AQI factors included in the study are total AQI, ozone, carbon monoxide, sulfur dioxide, and nitrogen dioxide $\left(\mathrm{NO}_{2}\right)$. Other demographic, socioeconomic, and geographic variables were included as covariates. The correlations of COVID-19 variables - proportion of cases and deaths in each population, as well as case fatality rate with independent variables were determined by Pearson and Spearman correlation and multiple linear regression analyses. The results revealed that $\mathrm{AQI}-\mathrm{NO}_{2}$, population density, longitude, gross domestic product per capita, median age, total death of disease, and pneumonia per population were significantly associated with the COVID-19 variables $(P<0.05)$. Air pollutants, especially $\mathrm{NO}_{2}$ in the US case, could be addressed as an important factor linked with COVID-19 susceptibility and mortality.
\end{abstract}

Keywords COVID-19 $\cdot$ Air quality index $\cdot$ Comorbidities $\cdot$ Population density $\cdot$ Longitude $\cdot$ Income

\section{Introduction}

The new coronavirus disease (COVID-19) pandemic has claimed more than 500,000 lives globally, causing massive public health and economic challenges (Liang et al. 2020; Conticini et al. 2020). This infectious disease, emerging in Wuhan, China, causes severe acute respiratory syndrome coronavirus 2 (SARS-CoV-2). The methods of contagion SARS-CoV-2 is not yet well understood, including what key modifiable parameters may contribute to spread of the virus.

Mohammad Sarmadi

sarmadim1@thums.ac.ir; msarmadi2@gmail.com

1 Department of Environmental Health Engineering, School of Health, Torbat Heydariyeh University of Medical Sciences, Torbat Heydariyeh, Iran

2 Health Sciences Research Center, Torbat Heydariyeh University of Medical Sciences, Torbat Heydariyeh, Iran

3 Department of Environmental Health Engineering, Neyshabur University of Medical Sciences, Neyshabur, Iran

4 Department of Epidemiology, Johns Hopkins Bloomberg School of Public Health, Baltimore, MD, USA

5 Energy and Environmental Technology and Economics, City University of London, London, UK
The risk factors for COVID-19 -associated severity and death are still under investigation, but some environmental and demographic factors such as air pollution (particle matter, nitrogen dioxide $\left(\mathrm{NO}_{2}\right)$, ozone $\left.\left(\mathrm{O}_{3}\right)\right)$ (Coccia 2020; Fattorini and Regoli 2020; Frontera et al. 2020; Liang et al. 2020), atmospheric patterns (temperature, humidity) (Sajadi et al. 2020; Sarmadi et al. 2020b), and comorbidities (cardiovascular and cerebrovascular disease, and cancer) (Richardson et al. 2020; Tian et al. 2020) might play a plausible role for both susceptibility and vulnerability of populations. The impact of mentioned parameters on excessive morbidity and mortality attributed to other respiratory or chronic diseases has been wellestablished in recent years (Liu et al. 2019; Shi et al. 2016; Wang et al. 2019; Grande et al. 2020). In order to investigate the correlation between air pollution indicators and various diseases, air quality index (AQI) can be considered as an important parameter that involves many air pollution elements. An analysis of 55 provinces capital in Italy recently revealed that increase in symptomatic COVID-19 infected cases was associated with variations in air pollution level (Coccia 2020). Also, other studies found that prevalence of comorbidities plays a key role in higher mortality of COVID-19 (Richardson et al. 2020; Tian et al. 2020; Ravi 2020). It also has been proven that some medical conditions like diabetes and heart diseases can increse the risk of death in COVID-19 patient (Richardson et al. 2020; Coccia 2020). Additionally, 
race and ethnicity were associated with the rate of death in different societies (Rentsch et al. 2020; Gross et al. 2020).

Regarding the possible contribution of air pollution and comorbidities in the risk of COVID-19 infection and mortality, this study aimed to assess the association between air pollutants and infection and mortality rate and whether race and comorbidities act modify the spread of COVID-19.

\section{Materials and methods}

\section{Study area, data, and sources}

This ecological study was conducted based on data from COVID-19 patients in all 50 US states; the District of Columbia (DC) and Puerto Rico. The USA (24-71 ${ }^{\circ} \mathrm{N}, 67-$ $172^{\circ} \mathrm{E}$ ) is situated at the North of America continent, covers an area of $9,833,520 \mathrm{~km}^{2}$, and has a population about $328,239,523$.

For this analysis, data was acquired from the Centers for Disease Control and Prevention (CDC) as the main source of COVID-19 descriptive statistics, including the proportion of cases per $10^{5}$ persons (PCP), deaths per $10^{5}$ persons (PDP), and case fatality rate (CFR).

\section{Measures of the study}

Parameters such as weighted distribution of population (\%) for race and comorbidities include septicemia, malignant neoplasms, diabetes mellitus, Alzheimer disease, influenza and pneumonia, chronic lower respiratory diseases, other diseases of the respiratory system, nephritis, nephrotic syndrome and nephrosis, diseases of heart, and cerebrovascular diseases compiled from the CDC for 22 weeks prior to June 6, 2020. Air quality and socioeconomic and demographic indicators were determined from the US Environmental Protection Agency's (EPA) AQI (USEPA 2020) and World Population Review website (World Population Review 2020), respectively.

\section{Data analysis procedure}

A descriptive analysis was conducted on all the data. Here, $t$ test and one-way ANOVA test were used to compare proportion of cases (PCI), proportion of deaths (PCD), and CFR values between states categories. Pearson and Spearman correlation, as well as linear regression analysis were conducted to assess the association between AQI, comorbidities, and demographic data and the number of cases and deaths from COVID-19 per 100,000 people. We have used logtransformed PCI and PCD as a dependent variable and mean AQI, weighted distribution of population in each state (\%), and number of previously mentioned diseases of interest in each population as independent variables. All the statistical analyses were 2-tailed and performed at a $5 \%$ significance level using SPSS 16 and Prism version 6 (GraphPad).

\section{Results and discussion}

While precise discussions about factors contributing to the novel coronavirus pandemic distribution are inconclusive, some plausible reasons for our findings were reviewed. Air pollution, comorbidities, and socioeconomic-demographic are main factors in contributing to the infection and mortality of COVID-19 spread in-between states of USA.

The number of cases and reported deaths per population in New York was much higher compared with other states $(402,914$ cases of $2,074,852$ individuals and 30,824 of 114,967 deaths) (Fig. 1). Table 1 showed the association of COVID-19 variables (PCI, PCD, and CFR) and some plausible factors contributing to the inter-states COVID-19 distribution. The association between AQI-NO ${ }_{2}$ and COVID-19 variables was statistically significant $(r=0.51$ for PCD, $r=0.46$ for PCI, and $r=0.40$ for CFR; $P<.05$ ). Also, population density (log density) and total mortality over 22 weeks were positively associated with PCI, PCD, and CFR $(P<.001)$, whereas longitude was inversely associated (Table 2 and Appendix). The correlations were stronger among $\mathrm{AQI}-\mathrm{NO}_{2}$, pneumonia deaths, population density, longitude, and PCD, suggesting these potential key factors may have considerably increased mortality rates.

With regard to high basic reproductive number $\left(\mathrm{R}_{0}\right)$ of COVID-19, it is apparent that states with high population density have a higher proportion of infected individuals and consequently high mortality rate, as described in previous studies (Wu et al. 2020; Rocklöv and Sjödin 2020). The number of total COVID-19 deaths (per population) is correlated with the population density, which is a troublesome issue. Increase in implemented control measures accompanied with increased hospital capacity and testing of asymptomatic patients could also impact the distribution scale of the virus between states (Lau et al. 2020; Conticini et al. 2020). Between January 19th (report first case) and June 12th, the results showed major infected cases and death numbers of COVID-19 to New York and New Jersey. At the same time (January 1st and June 6th), an explosion of total and pneumonia deaths per population within New Jersey State was detected. This state has the second highest density in the USA.

Air pollution elements such as $\mathrm{PM}_{2.5}, \mathrm{PM}_{10}, \mathrm{NO}_{2}$, and $\mathrm{O}_{3}$ are known to play an important role in both infectious and non-infectious diseases (Wang et al. 2019; Liu et al. 2019; Grande et al. 2020; Lin et al. 2007; Chang et al. 2020; Ciencewicki and Jaspers 2007). Some studies have also investigated the association between air pollution and incidence and distribution of COVID-19 in different other countries (Frontera et al. 2020; Fattorini and Regoli 2020). The air 
Table 1 Correlation $(r)$ between COVID-19 variables and independent variables

\begin{tabular}{|c|c|c|c|}
\hline Variable & $\log$ PCI & $\log$ PCD & CFR \\
\hline \multicolumn{4}{|l|}{ Air pollution } \\
\hline AQI-total & 0.110 & 0.079 & 0.035 \\
\hline AQI-Ozone & -0.252 & -0.283 & -0.233 \\
\hline $\mathrm{AQI}-\mathrm{SO}_{4}$ & 0.005 & 0.079 & 0.160 \\
\hline AQI-CO & 0.225 & 0.272 & 0.175 \\
\hline AQI-NO 2 & $0.464 * *$ & $0.513^{* *}$ & $0.399 *$ \\
\hline \multicolumn{4}{|l|}{ Race } \\
\hline Non-Hispanic Black or African American & 0.119 & 0.112 & 0.035 \\
\hline Non-Hispanic American Indian or Alaska Native & -0.281 & $-0.403 * *$ & $-0.370^{*}$ \\
\hline Non-Hispanic Asian & 0.112 & 0.135 & 0.078 \\
\hline \multicolumn{4}{|l|}{ Comorbidities } \\
\hline Total deaths ${ }^{\mathrm{a}}$ & $0.286^{*}$ & $0.366^{* *}$ & $0.328^{*}$ \\
\hline Pneumonia deaths ${ }^{\mathrm{a}}$ & $0.647 * *$ & $0.719 * *$ & $0.642 * *$ \\
\hline Influenza and pneumonia ${ }^{\mathrm{a}}$ & $0.355^{*}$ & $0.297 *$ & $0.295^{*}$ \\
\hline Nephritis nephrotic syndrome and nephrosis ${ }^{\mathrm{a}}$ & 0.235 & $0.306^{*}$ & $0.294 *$ \\
\hline Other diseases of respiratory system ${ }^{\mathrm{a}}$ & $0.383 * *$ & $0.465^{* *}$ & $0.411^{* *}$ \\
\hline Septicemia $^{a}$ & 0.219 & $0.358^{* *}$ & $0.358^{* *}$ \\
\hline \multicolumn{4}{|l|}{ Socioeconomic-demographic } \\
\hline Log density & $0.564 * *$ & $0.652 * *$ & $0.524^{* *}$ \\
\hline HDI & 0.230 & 0.218 & 0.188 \\
\hline GDP (\$US) & $0.395 * *$ & $0.375^{* *}$ & 0.224 \\
\hline Median age & -0.084 & 0.131 & $0.357 * *$ \\
\hline Longitude $\left(^{\circ}\right)$ & $-0.569 * *$ & $-0.612 * *$ & $-0.446^{* *}$ \\
\hline
\end{tabular}

Other race or comorbidities not significant with low correlation coefficient. $* * P<0.01, * P<0.05$

$A Q I$ air quality index, $P C P$ proportion of cases to population per $10^{5}, P D P$ proportion of deaths to population per $10^{5}, C F R$ case fatality rate (\%), $H D I$ human development index, GDP gross domestic product per capita (\$US)

${ }^{a}$ Deaths for 22 weeks as up June 6, 2020, per $10^{5}$ population

pollution associations revealed in this study were similar to that of prior studies in USA (Liang et al. 2020). A higher value of CFR and PCD was significantly associated with exposure to $\mathrm{NO}_{2}$, but not $\mathrm{O}_{3}$ and $\mathrm{PM}_{2.5}$ (Liang et al. 2020; Anil and
Alagha 2020; Islam et al. 2020). On the other hand, Wu et al. 2020 showed that only $1 \mu \mathrm{g} / \mathrm{m}^{3}$ increase in $\mathrm{PM}_{2.5}$ was associated with an eighth percent increase in the COVID-19 death rate. This study suggested that air pollution exposure may

Table 2 multivariable linear regression analysis between independent variables and COVID-19 variables (adjusted with HDI)

\begin{tabular}{|c|c|c|c|c|c|c|c|c|c|c|c|c|}
\hline \multirow[t]{2}{*}{ Variables } & \multicolumn{4}{|l|}{ PCI } & \multicolumn{4}{|l|}{ PCD } & \multicolumn{4}{|l|}{ CFR } \\
\hline & $\begin{array}{l}F- \\
\text { test }\end{array}$ & $B(\mathrm{SE})$ & $R^{2}$ & Sig. & $\begin{array}{l}F \text { - } \\
\text { test }\end{array}$ & $B(\mathrm{SE})$ & $R^{2}$ & Sig. & $\begin{array}{l}F \text { - } \\
\text { test }\end{array}$ & $B(\mathrm{SE})$ & $R^{2}$ & Sig. \\
\hline AQI-NO ${ }_{2}$ & 5.10 & $0.02(0.005)$ & 0.25 & 0.003 & 5.94 & $0.03(0.008)$ & 0.28 & 0.002 & 4.34 & $0.08(0.04)$ & 0.22 & 0.04 \\
\hline Log density & 8.65 & $0.24(0.06)$ & 0.26 & $<0.001$ & 19.47 & $0.45(0.008)$ & 0.44 & $<0.001$ & 16.18 & $1.77(0.36)$ & 0.40 & $<0.001$ \\
\hline Median age & 0.93 & $0.022(0.02)$ & 0.04 & 0.24 & 1.50 & $0.03(0.027)$ & 0.06 & 0.34 & 8.44 & $0.35(0.11)$ & 0.26 & 0.003 \\
\hline Longitude $\left({ }^{\circ}\right)$ & 9.81 & $-0.009(0.002)$ & 0.29 & $<0.001$ & 20.45 & $-0.02(0.003)$ & 0.46 & $<0.001$ & 16.55 & $-0.06(0.01)$ & 0.40 & $<0.001$ \\
\hline Total deaths ${ }^{\mathrm{a}}$ & 5.71 & $0.002(0.001)$ & 0.19 & 0.002 & 18.90 & $0.005(0.001)$ & 0.45 & $<0.001$ & 24.67 & $0.02(0.004)$ & 0.50 & $<0.001$ \\
\hline Pneumonia deaths ${ }^{\mathrm{a}}$ & 14.70 & $0.01(0.002)$ & 0.38 & $<0.001$ & 32.40 & $0.02(0.002)$ & 0.76 & $<0.001$ & 24.31 & $0.08(0.01)$ & 0.50 & $<0.001$ \\
\hline Influenza and pneumonia $^{\mathrm{a}}$ & 0.23 & $0.006(0.008)$ & 0.02 & 0.44 & 1.63 & $0.012(0.011)$ & 0.06 & 0.29 & 4.24 & $0.08(0.07)$ & 0.15 & 0.13 \\
\hline $\begin{array}{l}\text { Nephritis nephrotic syndrome and } \\
\text { nephrosis }^{\mathrm{a}}\end{array}$ & 0.62 & $-0.001(0.008)$ & 0.03 & 0.93 & 1.67 & $0.005(0.012)$ & 0.07 & 0.69 & 3.84 & $0.07(0.05)$ & 0.14 & 0.2 \\
\hline $\begin{array}{l}\text { Other diseases of respiratory } \\
\text { system }^{\text {a }}\end{array}$ & 2.22 & $0.021(0.01)$ & 0.11 & 0.04 & 8.37 & $0.05(0.02)$ & 0.26 & 0.001 & 11.60 & $0.27(0.07)$ & 0.33 & $<0.001$ \\
\hline Septicemia $^{\mathrm{a}}$ & 2.44 & $0.03(0.01)$ & 0.10 & 0.04 & 7.57 & $0.07(0.02)$ & 0.26 & 0.001 & 14.48 & $0.35(0.08)$ & 0.40 & $<0.001$ \\
\hline
\end{tabular}

$A Q I$ air quality index, $P C P$ proportion of cases to population per $10^{5}, P D P$ proportion of deaths to population per $10^{5}, C F R$ case fatality rate (\%), $H D I$ human development index

$* * P<0.01, * P<0.05$

${ }^{\mathrm{a}}$ Deaths for 22 weeks as up June 6,2020 , per $10^{5}$ population 

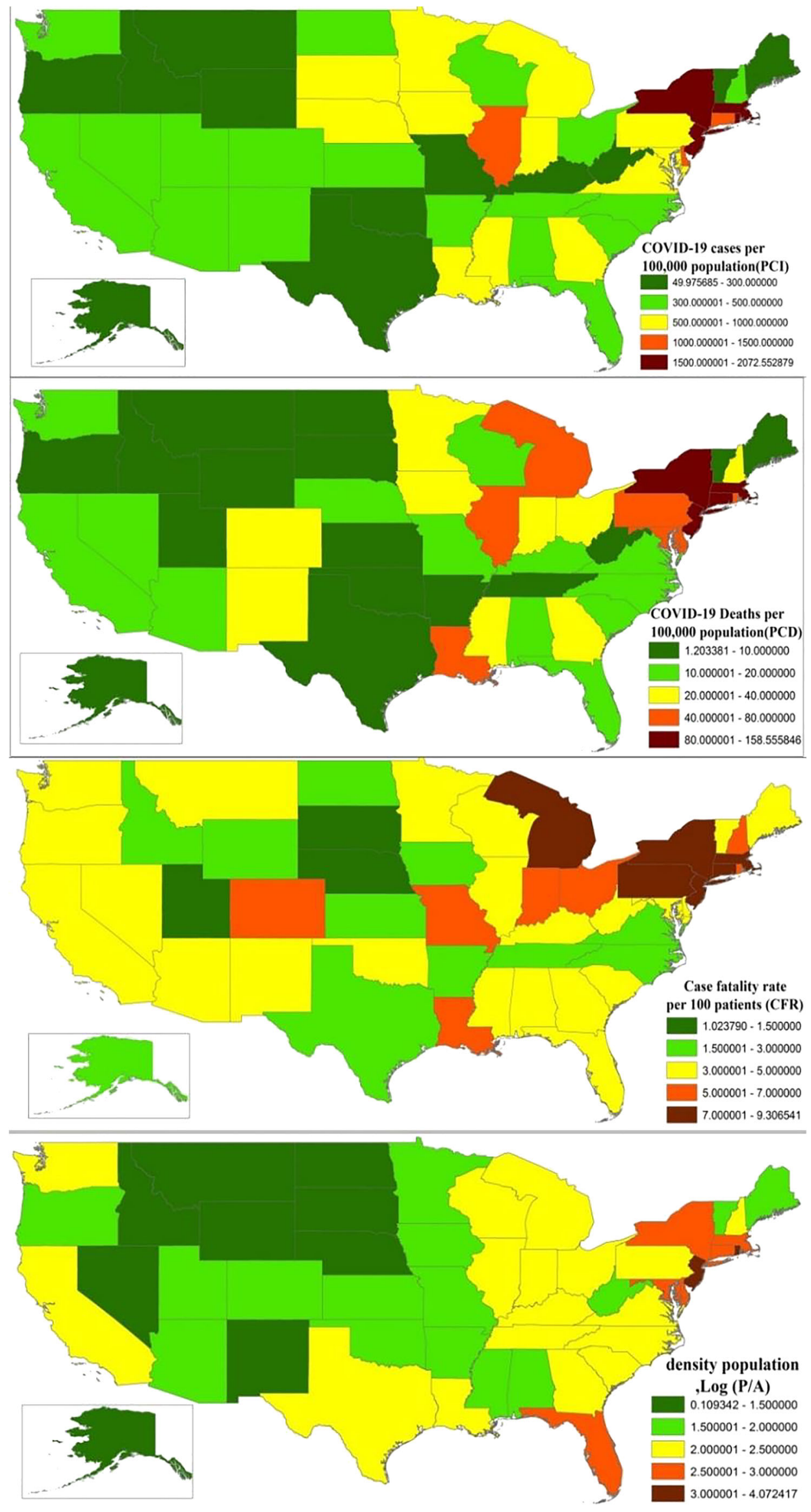
Fig. 1 Geographical distribution of the proportion of cases (PCI), deaths (PCD) per 100,000 population, case fatality rate (\%) (updated June 12, 2020) and density population (logarithm population per area $\left(\mathrm{km}^{2}\right)$

suppress early immune response to infection through inflammation and cellular damage (Wu et al. 2020), in line with other infectious diseases such as SARS (Cui et al. 2003).

The results of current study showed that longitude was negatively correlated with COVID-19 variables (Appendix). In fact, states in the western USA (high longitude) had lower median age, comorbidities, and air pollution as well as population density (Fig. 1). On the other hand, GDP per capita was positively correlated with PCI and PCD. It appears that the investment in health systems of regions with higher income may support screening programs and tests for fast and high volume diagnosis of patients infected with COVID-19 and/ or asymptomatic individuals, and vice versa (Chattu and Yaya 2020; Vasquez et al. 2020; Sarmadi et al. 2020a). Additionally, it seems that prevalence of comorbidities plays a determinative role in COVID-19 incidence and mortality. Similarly, prevalence of heart disease and diabetes was positively associated with risk of death in other studies (Richardson et al. 2020; Coccia 2020).

We acknowledge that there are some limitations to this study as follows: The data for number of cases and deaths attributed to COVID-19 are invariably different in each state due to differences in diagnosis criteria, variation in the number of available tests in each state, different sensitivity and specificity of each test, and reporting protocols. Other potential factors discussed in the studies (Sajadi et al. 2020; Sarmadi et al. 2020b). It is also suggested that future studies should address the effect of quarantine policies, adherence, and effectiveness, public awareness, social distancing, length of hospitalization, migration, and other chronic disease.

\section{Conclusion}

Despite the inherent limitations of the ecological study design utilized and our subsequent inability to assess associations at an individual and temporal level, our study suggested that air pollution components, especially $\mathrm{NO}_{2}$, could be contributing factors in the interstate distribution of COVID-19. Population density might be also an effective factor in COVID-19 outbreak. Alongside demographic factors, wearing facemasks and adhering to social and physical distancing guideline are imperative to limit spreading the disease. We also acknowledge that higher incidence rates in some states reflect economic differences, which may impact access and availability of diagnostic services and healthcare provisions. It also seems that Non-Hispanic American Indian or Alaska Native are more resistant against COVID-19. Finally, we believe that health managers and policymakers in the USA should consider the implemented measurements based on social distancing, school closures, and funding for hospital infrastructure, which has the ability to slow the spread of disease, with special attention to providing education and resources to vulnerable and historically marginalized populations with disproportionate exposures to air pollution.

Acknowledgments The authors would like to thank the Torbat Heydariyeh University of Medical Sciences for their support for performing this research.

Authors' contributions Mohammad Sarmadi: conceptualization, methodology, formal analysis, investigation, project administration, resources, data curation, writing - original draft, writing - review and editing, supervision. Vahid Kazemi Moghadam: conceptualization, investigation, writing-original draft, writing-review and editing. Aisha S. Dickerson: methodology, formal analysis, investigation, writing original draft, writing - review and editing. Luigi Martelletti: investigation, writing — original draft, writing - review and editing. All authors read and approved the manuscript.

Data availability All data generated or analyzed during this study are included in this published article.

\section{Compliance with ethical standards}

Conflict of interest The authors declare that they have no competing interests.

Ethics approval and consent to participate Not applicable.

Consent for publication Not applicable.

Abbreviations AQI, air quality index; CDC, The Centers for Disease Control and Prevention; CFR, case fatality rate; COVID-19, coronavirus disease 2019; EPA, Environmental Protection Agency; GDP, gross domestic product; $\mathrm{NO}_{2}$, nitrogen dioxide; $\mathrm{O}_{3}$, ozone; $\mathrm{PCP}$, proportion of cases per population; PDP, proportion of death per population; PM, particle matter; SARS-CoV-2, severe acute respiratory syndrome coronavirus 2; USA, United States of America

\section{Appendix}

Scatter plots show standardize coefficients of liner regression model between COVID-19 and independent variables 

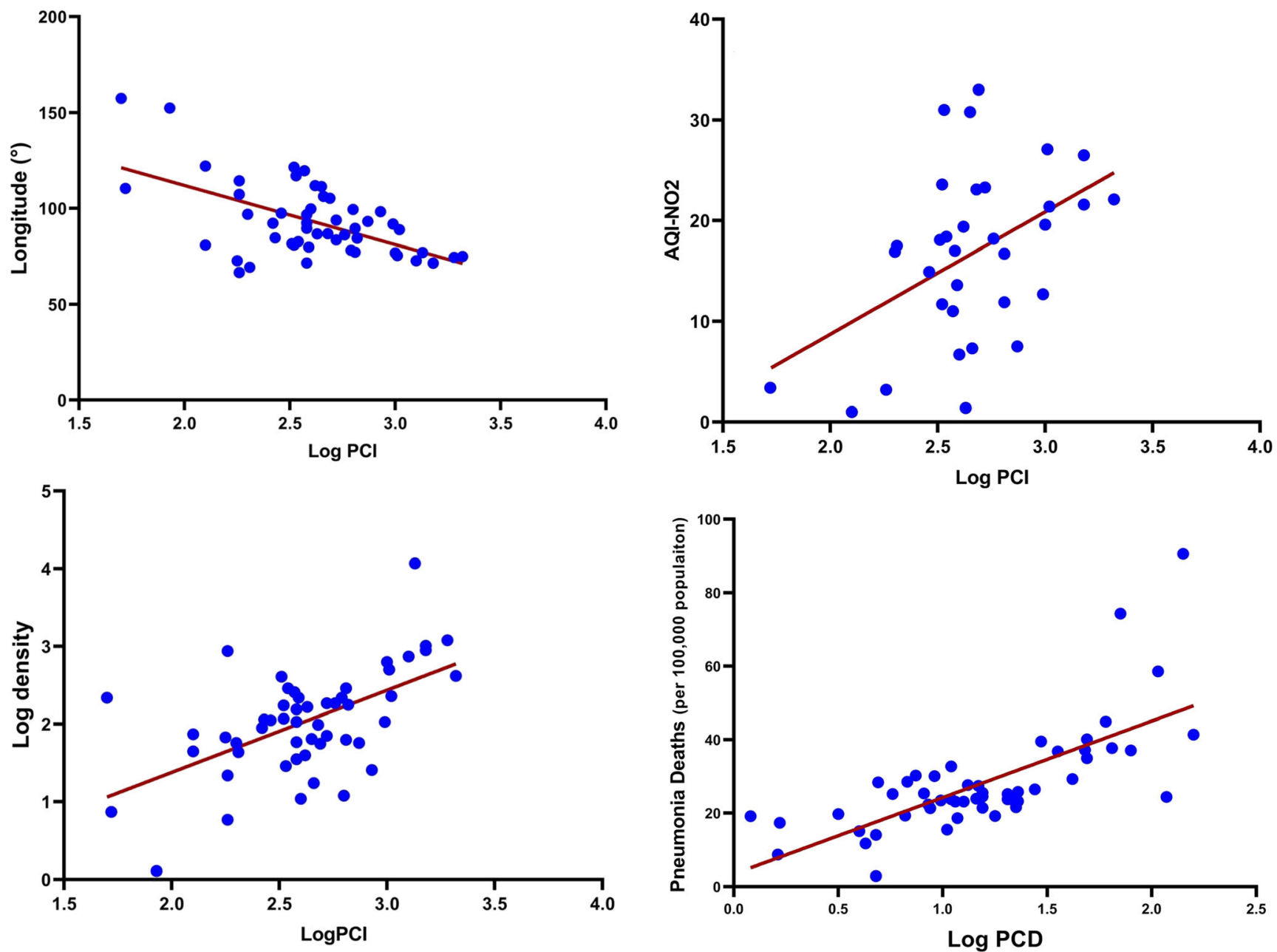

Fig. 2 Scatter plots show liner regression model between COVID-19 and independent variables AQI air quality index, PCP proportion of cases to population per 105, PDP proportion of deaths to population per 105, CFR case fatality rate (\%), HDI human development index, GDP gross domestic product per capita (\$US)

Fig. 2 (continued) 

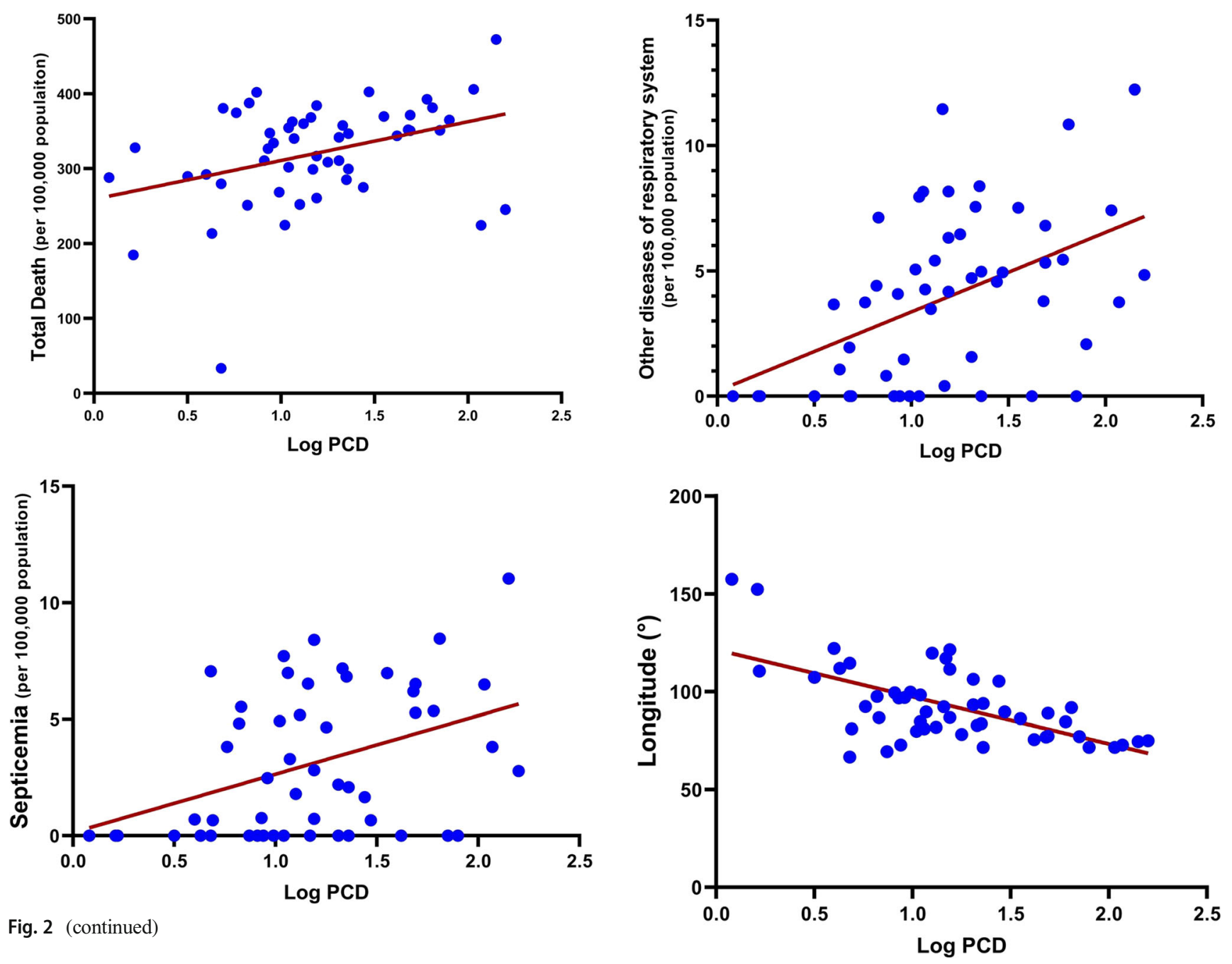

Fig. 2 (continued)

Fig. 2 (continued) 

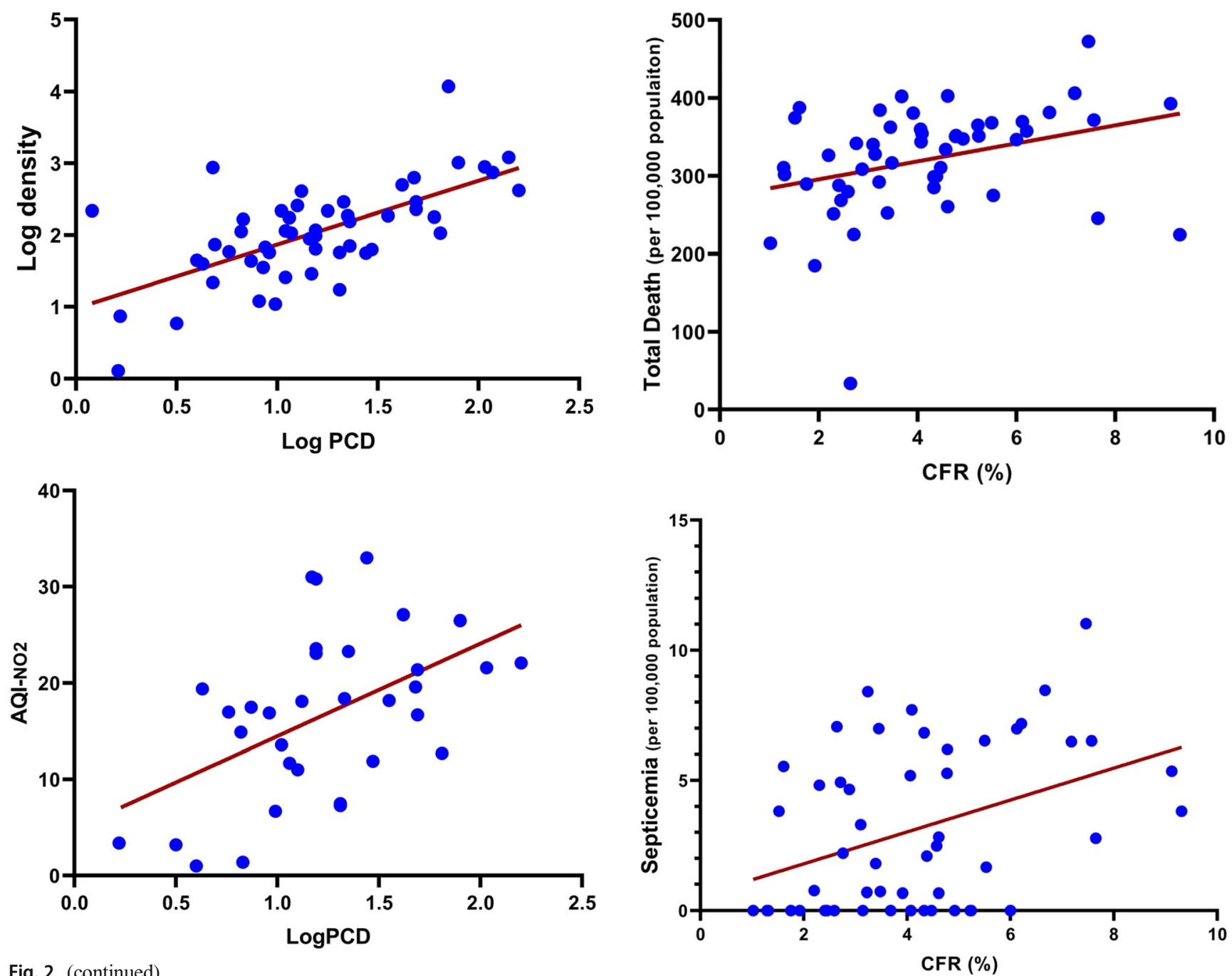

Fig. 2 (continued)

Fig. 2 (continued) 

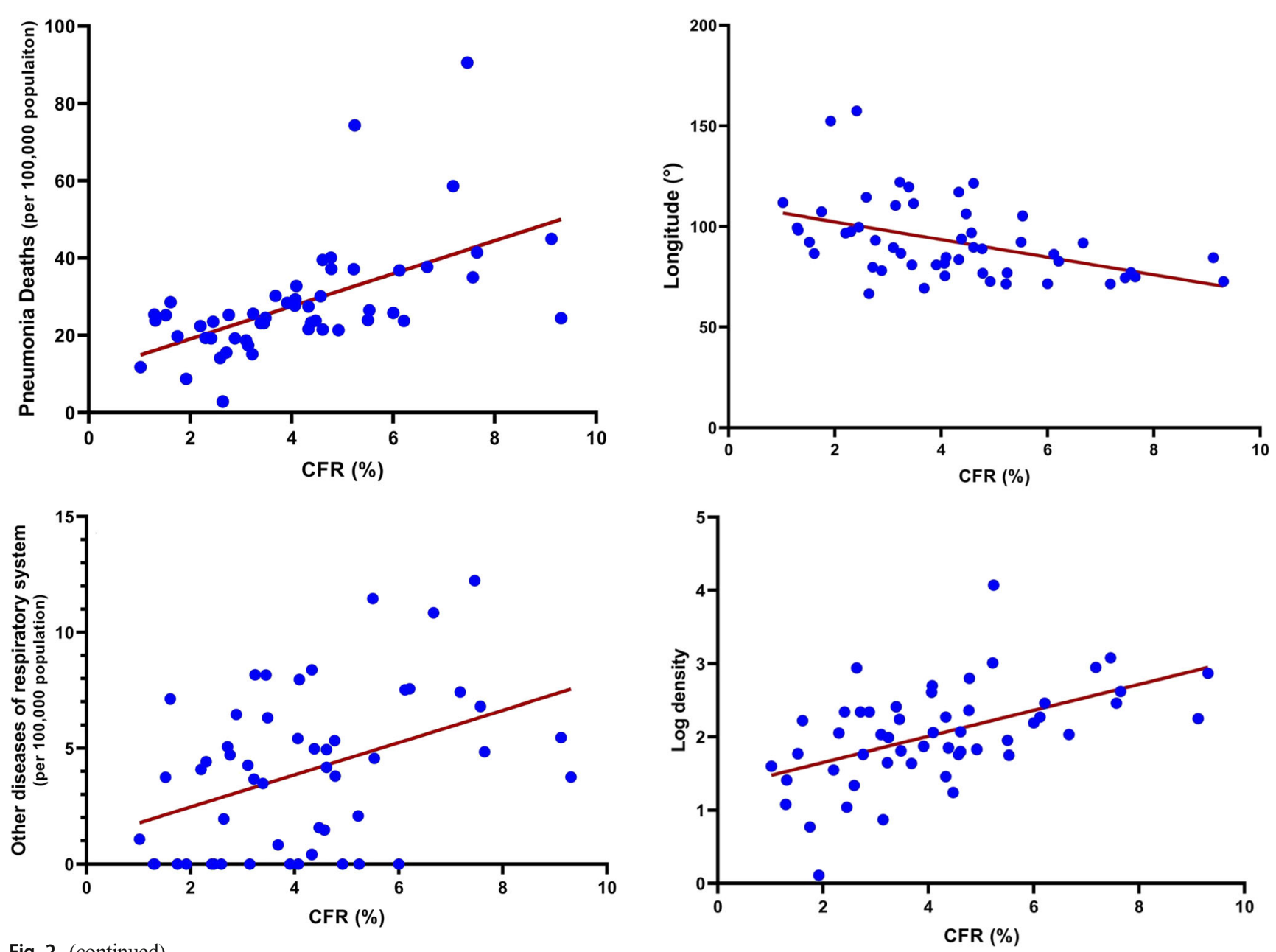

Fig. 2 (continued)

Fig. 2 (continued) 

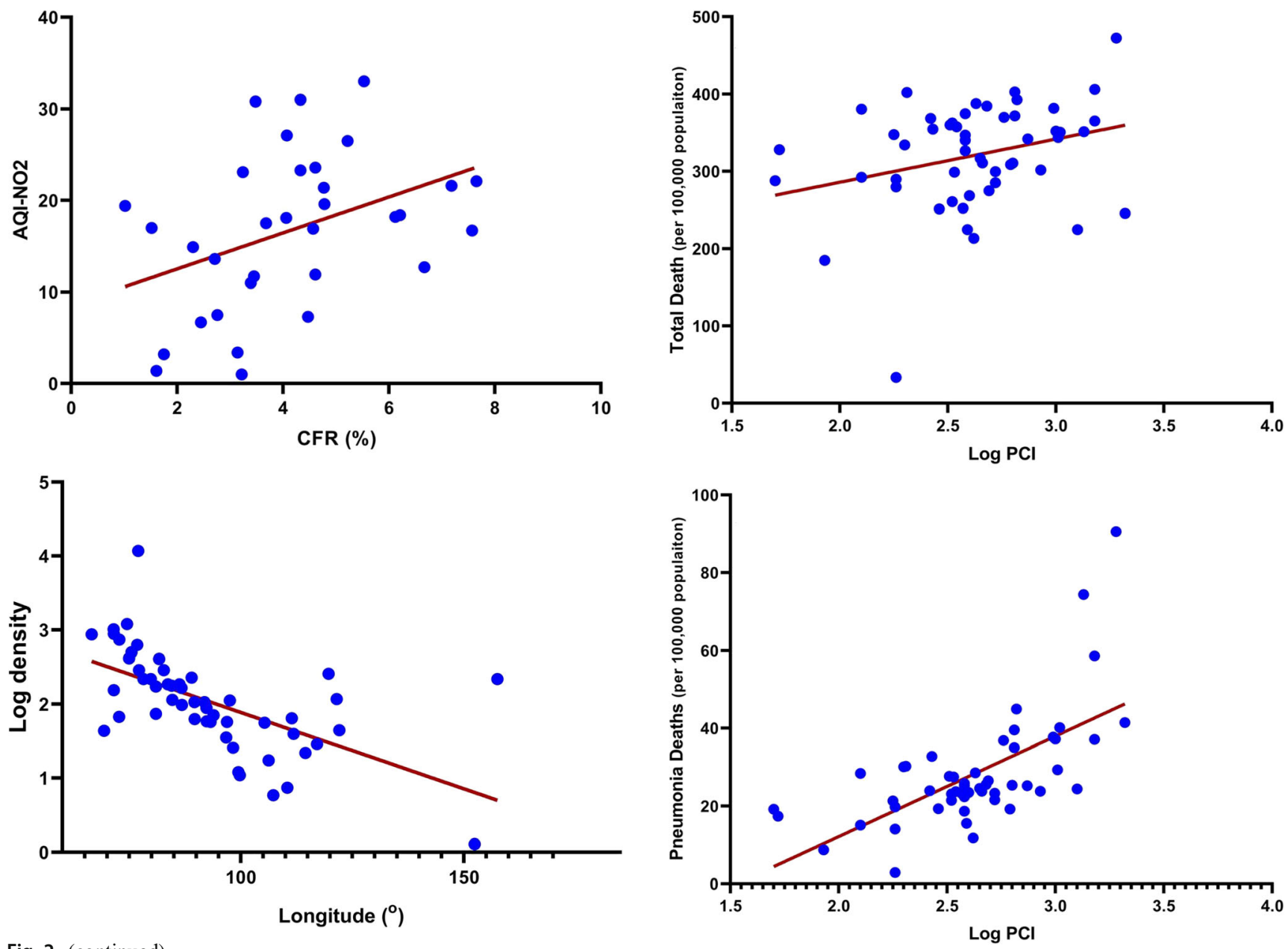

Fig. 2 (continued)

Fig. 2 (continued)

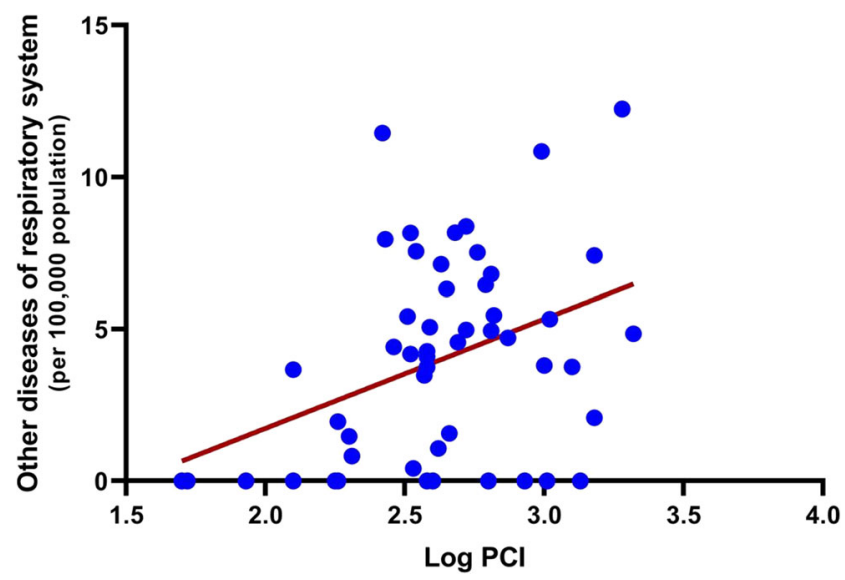

Fig. 2 (continued) 


\section{References}

Anil I, Alagha O (2020) The impact of COVID-19 lockdown on the air quality of Eastern Province. Air Qual Atmos Health, Saudi Arabia. https://doi.org/10.1007/s11869-020-00918-3

Chang Q, Zhang H, Zhao Y (2020) Ambient air pollution and daily hospital admissions for respiratory system-related diseases in a heavy polluted city in Northeast China. Environ Sci Pollut Res 27: 10055-10064

Chattu VK, Yaya S (2020) Emerging infectious diseases and outbreaks: implications for women's reproductive health and rights in resourcepoor settings. Reprod Health 17:43

Ciencewicki J, Jaspers I (2007) Air pollution and respiratory viral infection. Inhal Toxicol 19:1135-1146

Coccia M (2020) Factors determining the diffusion of COVID-19 and suggested strategy to prevent future accelerated viral infectivity similar to COVID. Sci Total Environ. 729-138474. https://doi.org/10. 1016/j.scitotenv.2020.138474

Conticini E, Frediani B, Caro D (2020) Can atmospheric pollution be considered a co-factor in extremely high level of SARS-CoV-2 lethality in Northern Italy? Environ Pollut 261:114465

Cui Y, Zhang Z-F, Froines J, Zhao J, Wang H, Yu, S.-Z. \& Detels, R. (2003) Air pollution and case fatality of SARS in the People's Republic of China: an ecologic study. Environ Health 2:15

Fattorini D, Regoli F (2020) Role of the chronic air pollution levels in the Covid-19 outbreak risk in Italy. Environ Pollut 264:114732

Frontera A, Martin C, Vlachos K, Sgubin G (2020) Regional air pollution persistence links to COVID-19 infection zoning. J Inf Secur S01634453(20):30173

Grande G, Ljungman PL, Eneroth K, Bellander T, Rizzuto D (2020) Association between cardiovascular disease and long-term exposure to air pollution with the risk of dementia. JAMA Neurol 77:9

Gross CP, Essien UR, Pasha S, Gross JR, Wang SY, Nunez-Smith M (2020) Racial and ethnic disparities in population-level covid-19 mortality. Journal of general internal medicine, 1-3.

Islam MS, Tusher TR, Roy S, Rahman M (2020) Impacts of nationwide lockdown due to COVID-19 outbreak on air quality in Bangladesh: a spatiotemporal analysis. Air Qual Atmos Health. https://doi.org/ 10.1007/s11869-020-00940-5

Lau H, Khosrawipour V, Kocbach P, Mikolajczyk A, Ichii H, Zacharski M, Bania J, Khosrawipour T (2020) The association between international and domestic air traffic and the coronavirus (COVID-19) outbreak. J Microbiol Immunol Infect 53:467-472

Liang D, Shi L, Zhao J, Liu P, Schwartz J, Gao S, Sarnat J, Liu Y, Ebelt S, Scovronick N (2020) Urban Air Pollution May Enhance COVID-19 Case-Fatality and Mortality Rates in the United States. The Innovation 100047. https://doi.org/10.1016/j.xinn.2020.100047

Lin H-H, Ezzati M, Murray M (2007) Tobacco smoke, indoor air pollution and tuberculosis: a systematic review and meta-analysis. PLoS Med 4:17

Liu C, Chen R, Sera F, Vicedo-Cabrera AM, Guo Y, Tong S, Coelho MS, Saldiva PH, Lavigne E, Matus P (2019) Ambient particulate air pollution and daily mortality in 652 cities. N Engl J Med 381: $705-715$

Ravi K (2020) Ethnic disparities in COVID-19 mortality: are comorbidities to blame? Lancet 396(10243):22. https://doi.org/10.1016/ S0140-6736(20)31423-9
Rentsch CT, Kidwai-Khan F, Tate JP, Park LS, King JT, Skanderson M, Hauser RG, Schultze A, Jarvis CI, Holodniy M, Lore V, Akgun KM, Crothers K, Taddei TH, Freiberg MS, Justice AC (2020) Covid-19 by race and ethnicity: a national cohort study of 6 million United States veterans. medRxiv: The Preprint Server for Health Sciences. https://doi.org/10.1101/2020.05.12.20099135

Richardson S, Hirsch JS, Narasimhan M, Crawford JM, Mcginn T, Davidson KW, Consortium ATNCR (2020) Presenting characteristics, comorbidities, and outcomes among 5700 patients hospitalized with COVID-19 in the New York City area. JAMA 323:2052-2059

Rocklöv J, Sjödin H (2020) High population densities catalyse the spread of COVID-19. J Travel Med 27:2

Sajadi MM, Habibzadeh P, Vintzileos A, Shokouhi S, Miralles-Wilhelm F, Amoroso A (2020) Temperature, humidity, and latitude analysis to estimate potential spread and seasonality of coronavirus disease 2019 (COVID-19). JAMA Netw Open 3:e2011834-e2011834

Sarmadi M, Kakhki S, Foroughi M, Abadi TSH, Nayyeri S, Moghadam VK, Ramezani M (2020a) Hospitalization period of COVID-19 for future plans in hospital. BJS (Brit J Surg) 107:e427-e428

Sarmadi M, Marufi N, Kazemi Moghaddam V (2020b) Association of COVID-19 global distribution and environmental and demographic factors: an updated three-month study. Environ Res 188:109748

Shi L, Zanobetti A, Kloog I, Coull BA, Koutrakis P, Melly SJ, Schwartz JD (2016) Low-concentration PM2. 5 and mortality: estimating acute and chronic effects in a population-based study. Environ Health Perspect 124:46-52

Tian J, Yuan X, Xiao J, Zhong Q, Yang C, Liu B, Cai Y, Lu Z, Wang J, Wang Y, Liu S, Cheng B, Wang J, Zhang M, Wang L, Niu S, Yao Z, Deng X, Zhou F, Wei W, Li Q, Chen X, Chen W, Yang Q, Wu S, Fan J, Shu B, Hu Z, Wang S, Yang X-P, Liu W, Miao X, Wang Z (2020) Clinical characteristics and risk factors associated with COVID-19 disease severity in patients with cancer in Wuhan, China: a multicentre, retrospective, cohort study. Lancet Oncol 21: 893-903

USEPA (2020) Air data: air quality data collected at outdoor monitors across the US [online]. USA. Available: https://www.epa.gov/ outdoor-air-quality-data [Accessed 15 June 2020]

Vasquez L, Sampor C, Villanueva G, Maradiegue E, Garcia-Lombardi M, Gomez-García W, Moreno F, Diaz R, Cappellano AM, Portilla CA (2020) Early impact of the COVID-19 pandemic on paediatric cancer care in Latin America. Lancet Oncol 21:753-755

Wang M, Hou Z-H, Xu H, Liu Y, Budoff MJ, Szpiro AA, Kaufman JD, Vedal S, Lu B (2019) Association of estimated long-term exposure to air pollution and traffic proximity with a marker for coronary atherosclerosis in a nationwide study in China. JAMA Netw Open 2:e196553-e196553

World Population Review (2020) Median Age by State 2020 [Online]. Available: https://worldpopulationreview.com/states/median-ageby-state/ [Accessed 15June 2020]

Wu X, Nethery RC, Sabath BM, Braun D, Dominici F (2020) Exposure to air pollution and COVID-19 mortality in the United States. medRxiv: The Preprint Server for Health Sciences. https://doi.org/ $10.1101 / 2020.04 .05 .20054502$

Publisher's note Springer Nature remains neutral with regard to jurisdictional claims in published maps and institutional affiliations. 